\title{
Human Resource Function Competencies in European Companies
}

\author{
Paul Boselie \\ Jaap Paauwe
}

Working Paper 05 - 08 


\title{
Human Resource Function Competencies in European Companies
}

\author{
Paul Boselie \\ Rotterdam School of Economics Erasmus University \\ boselie@few.eur.nl \\ Jaap Paauwe \\ Rotterdam School of Economics \\ Department of Business \& Organization, H15-10 \\ Erasmus University Burg. Oudlaan 50 \\ 3062 PA Rotterdam \\ The Netherlands \\ Tel. +31-10-4082542 \\ or $+31-10-4081366$ \\ paauwe@few.eur.nl
}

http://www.ilr.cornell.edu/cahrs

This paper has not undergone formal review or approval of the faculty of the ILR School. It is intended to make results of Center research available to others interested in preliminary form to encourage discussion and suggestions.

Most (if not all) of the CAHRS Working Papers are available for reading at the Catherwood Library. For information on what's available link to the Cornell Library Catalog:

http://catalog.library.cornell.edu if you wish. 


\begin{abstract}
This paper presents an overview of recent empirical research on human resource competencies in Europe. The data were collected in 2002 in the global Human Resource Competence Study, an initiative of the University of Michigan. The results suggest that personal credibility and HR delivery have a positive effect on the relative ranking of the HR function and its professionals. According to non-HRM respondents strategic contribution is the competency that will lead to financial competitiveness, while HR managers consider business knowledge to be crucial for added value of the HR function.
\end{abstract}

Key words

Human resource management, HR function, competencies 


\section{Human Resource Function Competencies in European Companies}

\section{Introduction}

Based on the increased interest for the relationship between HRM and performance (e.g. Guest, 1997; Boselie et al., 2001), we can discern a heightened interest in the kind of roles and competencies the HR-manager him or herself should display in order to add value to performance as well (e.g. Huselid et al., 1997; Teo, 2002). So the focus is not only on the kind of HR policies and practices and how they are aligned horizontally and vertically (e.g. Huselid, 1995), but on the kind of capabilities, which need to be fulfilled by those who feel attracted to the HR-function as a specialist staff job as well. Whereas in the past the debate mainly evolved around the different HR roles and subsequent shifts in it, we recently see a more empirically based trend, which tries to establish the necessary competencies on the basis of the demands of the main stakeholders. This is the kind of data, which lies at the heart of our analysis in this paper. Our empirical results are embedded in the Human Resource Competence Survey (Brockbanck and Ulrich, 2002). This survey has led to the summing up of five domains of competencies, which are crucial for the HR function and its effectiveness. In this paper we will analyze the data for the European context.

Worldwide socio-economic developments, such as globalization, increasing speed towards a service economy, changes in workforce demographics, focus on customer loyalty, and emphasis on financial performance (Brockbanck et al., 2002), challenge the HR function in its role for creating added value to the organization. Ulrich (1997) emphasizes the importance of the development of HRM professionals, in particular in their different roles towards HR leadership in an organization. In the 1990s the Human Resource Competence Study (HRCS), an initiative of the University of Michigan, focused on organizations in the USA. These data provide a rich source of information on key competencies for the HR function. The survey has been carried out repeatedly (in 1988, 1992 and 1997) and every time the research team at 
Michigan Business School intensified the co-operation with partners around the globe. The 2002 HRCS also included the European context for the first time. Both Michigan Business School and Rotterdam School of Management agreed to work together on the basis of the format developed by the research team of Michigan Business School.

The European empirical survey data ( $n=683$ individual respondents) were collected in 2002 and stem from multinational companies (40 MNC's in total) operating in different industries (e.g. manufacturing, financial services) located in European countries (e.g. United Kingdom, the Netherlands, Switzerland, Germany). In the survey the main focus was on the following key issues: First, what are the main competencies for the HRM function (and its HR professionals) perceived by relevant clients in an organization (the HRM staff and the line managers) in Europe? Second, what is the perceived added value of these HRM competencies to the performance of an organization?

First we will give an overview of the various HR roles, as described and discussed in the last two decades. Based on the global HRCS-outcomes of 2002 we will describe the five main domains of competencies and how they relate to performance. Subsequently we proceed with the European part of the data set in more detail in order to establish whether the global results repeat themselves in an European context. In our concluding section we critically discuss our findings and indicate possible venues for future research, which is in need of both a more critical and a more context embedded perspective.

\section{Changing roles and expectations for the HR manager}

The readjustment and recalibration of the HR function and the different roles of HR professionals has been going on for some time. A review of the literature throws up many frameworks for considering the evolution and development in HRM tasks, skills and roles. Some are merely a listing of things that HRM specialists do, while other are more encompassing, considering the HRM pattern from a more ideal type perspective (Tyson and Fell, 1986; Ulrich, 1997). Tyson (1987) provides a good start for our 
overview of the changing roles. Tyson (1987), struck by the increased fragmentation of the personnel function, which he describes as its 'Balkanization, 'distinguishes three Weberian ideal types or models:

(1) The clerk of works model. Personnel management is an administrative support activity with no involvement in business planning. All authority is vested in line managers. The principal activities for these personnel staff will be recruitment, record keeping, and welfare.

(2) The contract manager model. This approach is concerned with confronting unions with a regulatory system, as part of a comprehensive policy network.

Acting on behalf of line managers, the personnel department staff is the expert in the trade union agreements, in fixing-day-to day issues with the unions, and responding in a reactive way to problems.

(3) The architect model. In this model personnel executives seek to create and build the organization as a whole. This creative vision of personnel means contributing to the success of the business through explicit policies, which seek to influence the corporate plan, with an integrated system of controls between personnel and line managers. The personnel function is represented within the dominant coalition in the organization.

Schuler (1990) increasingly discerns a shift from a specialist staff function to the HR manager as business manager and part of the management team. He claims the following roles to become more prominent in the nineties: business person, shaper of change, consultant to the organization, strategy formulator and implementer, talent manager, assets manager and cost controller (Schuler, 1990).

Carroll (1991) also envisages a shift in HRM roles, as a consequence of the more pronounced links to business needs and a greater requirement to contribute to organizational effectiveness. In addition to the traditional roles of policy formulator and provider of personnel services, Carroll (1991) expects certain roles to take on greater importance:

(1) Delegator. This role enables line management to serve as primary implementers of HRM systems. 
(2) Technical expert. This function encompasses a number of highly specific HRrelated skills in for example areas like remuneration, and management development. (3) Innovator. As innovators, HR managers recommend new approaches to solving HRM-related problems, such as productivity and a sudden increase in absenteeism due to illness.

Storey (1992), intensively involved in the HRM characteristics debate in the UK in both the eighties and nineties, develops the following typology based on (a) action orientation (interventionary versus non-interventionary) and (b) strategic versus tactical choices/ considerations. These two dimensions lead to the following four different HR roles:

(1) Advisors act as internal consultants. They are in tune with recent developments, but leave the actual running to line and general management colleagues.

(2) Handmaidens are primarily customer oriented in the services they offer, based on a rather subservient, attendant relationship towards line management.

(3) Regulators are more interventionary. They formulate, promulgate and monitor observance of employment rules. These rules range from personnel procedure manuals to joint agreements with trade unions.

(4) Change makers are seeking to put relationships with employees on a new footing, one that is in line with the 'needs of the business.'

Finally we refer to the typology developed by Ulrich (1997) who also uses two dimensions (people versus process and strategic versus operational) in order to highlight the following roles by which the HR managers can contribute to added value:

(1) Administrative expert. In this role the HR professional designs and delivers efficient HR processes for staffing, training, appraising, rewarding, promoting, and otherwise managing the flow of employees through the organization. The deliverable from this role is administrative efficiency.

(2) Employee champion. The employee contribution role for HR professionals encompasses their involvement in the day-to-day problems, concerns and needs of employees. The deliverables aimed at are increased employee commitment and competence.

(3) Change agent. This role focuses on managing transformation and change. The 
deliverable is aimed at developing a capacity for change. HR managers help employees to let go of old and adapt to a new culture.

(4) Strategic Partner. The strategic HR role focuses on aligning HR strategies and practices with business strategy. The deliverable is strategy execution. HR practices help accomplish business objectives.

Reflecting on this overview of different typologies, as has been put forward during the eighties and nineties, we can wonder if they still have any relevance and significance for today's practice. Authors like Schuler, Carroll and Tyson all discern a shift towards a more strategic, business-like approach and a more intensive relationship with line and top management. This is fully in line with all the writings on (strategic) human resource management as encountered during that same period. However the balance seems to be restored by the typology of Storey (1992), which is more empirically based than the aforementioned typologies. In his overview we still encounter the 'handmaidens' and 'regulators, both of which are more reminiscent of the traditional personnel management role, which apparently happened to be still quite common in practice. Based on more recent empirical data (both survey-based and interviews) Caldwell (2003) re-examines the relevance of the typology as put forward by Storey. His conclusion is that the regulator role appears to have declined and that the advisor role has become more strongly entrenched. The service provider role (a renaming of Storey originally 'handmaiden' role in order to avoid any overly negative meaning, see Caldwell, 2003) has been remodeled to deliver the administrative infrastructure of HR more effectively. Finally the change agent role has grown in significance along with the ascendancy of HRM (Caldwell, 2003).

Reflecting on both the typology of Storey and Ulrich, Caldwell claims that using these kind of generic roles have intrinsic weaknesses, because they do not capture the increasingly complex and multi-facetted nature of personnel and HR roles. Based on his empirical research (especially the qualitative part) he is indeed able to establish a range of role ambiguities and conflicts. Making use of a two by two matrix has on the one hand the charm of simplicity and expressiveness, but on the other hand generates indeed the problem of oversimplification by 
disguising the complexity of empirical reality. We can avoid this by making use of 'competencies' as is the case in the Human Resource Competence Survey. A survey which not only focuses on the USA (Ulrich) or on the UK (Storey, Caldwell) but is truly global in nature, at least since its' 2002 version. So it is high time to establish what's going on in practice - not just in the USA or UK, but across the globe - and what kind of competencies are involved in making the difference between high and low performing companies and HR-professionals.

\section{The Human Resource Competence Study 2002}

The Human Resource Competency Study (HRCS) has been an ongoing research project since 1988. Major blocks of data were gathered and analyzed in 1988, 1992 and 1997 in the USA (Brockbanck et al., 2002). In the 1988 and 1992 rounds, three competency categories were uncovered: business knowledge, HR functional capability and change management. In 1997, two additional categories were added: culture management and personal credibility. In 2002 the HRCS Michigan research team and its associated partners around the globe performed research in four continents: North America, Latin America, Asia and Europe. In the 2002 survey, out of a range of 78 items and 15 distilled competencies, five domain factors emerged as making a difference in terms of performance as indicated by the following two items:

- $\quad$ 'Relative ranking of the perceived HR-function performance' (Overall, compared with the other HR professionals whom you have known, how do you compare?) - $\quad$ 'Financial competitiveness' (Compared to the major competitor in "your business" in the last three years, how has "your business" performed financially?) The five domain factors, making a difference, are strategic contribution, personal credibility, HR delivery, business knowledge, and HR technology (Brockbank and Ulrich, 2002, internet).

Strategic Contribution. High-performing companies have HR professionals involved in the business at a strategic level. These HR professionals manage culture, facilitate fast change, are involved in the strategic decision-making and create market-driven connectivity. These four factors - culture management, strategic decision-making, fast change, and market driven 
connectivity - together comprise the HR competency domain of Strategic Contribution.

Personal Credibility. HR professionals must be credible to both their HR counterparts and the business line managers whom they serve. They need to have effective relationships with key people both inside and outside their business. They need to promise and deliver results and establish a reliable track record. In addition, HR professionals must have effective written and verbal communication skills. The three factors effective relationships, gets results, and personal communication, determine the domain of Personal Credibility.

HR Delivery. HR professionals deliver both traditional and operational HR activities to their business in four major categories:

- Development: designing developmental programs and challenging work experiences, offering career planning services, and facilitating internal communication processes. These efforts include both individual development as well as organization-wide development.

- Structure and HR Measurement: restructuring the organization, measuring impact of HR practices, and managing global implications of HR practices. ${ }^{\circ}$ Staffing: attracting, promoting, retaining, and outplacing appropriate people. ${ }^{\circ}$ Performance Management: designing performance-based measurements and reward systems and providing competitive benefit packages.

Business Knowledge. To become key players in the organization, HR professionals must understand the business and industry of the company they serve. Key areas of knowledge include applied understanding of the integrated value chain (how the firm horizontally integrates) and the firm's value proposition (how the firm creates wealth). The factor labour, representing institutional constraints such as labour legislation, is the third factor that constitutes the domain of Business Knowledge.

HR Technology. Technology is increasingly becoming a part of the workplace and as a delivery vehicle for HR services. HR professionals need to be able to leverage technology for HR practices and use e-HR/web-based channels to deliver value to their customers. 
Prior research of the global Human Resource Competency Survey suggests that all five domains of competencies have a positive impact on the performance of an organization. In the Global HRCS 2002 the Michigan research team - Wayne Brockbanck and Dave Ulrich - report significant impact of all five domains on the 'perceived relative ranking of the HRM managers' and a positive effect of four domains, except for HR technology, on 'financial competitiveness' of an organization. These results of the global HRCS can be summarized as follows:

- Strategic contribution has a positive $\mathrm{R}^{2}$ of 0.38 with relative ranking of the HRM manager and a positive $\mathrm{R}^{2}$ of 0.05 with financial performance. -Personal credibility has a positive $\mathrm{R}^{2}$ of 0.49 with relative ranking of the HRM manager and a positive $R^{2}$ of 0.03 with financial performance. - HR delivery has a positive $R^{2}$ of 0.31 with relative ranking of the HRM manager and a positive $R^{2}$ of 0.02 with financial performance. -Business knowledge has a positive $R^{2}$ of 0.19 with relative ranking of the HRM manager and a positive $R^{2}$ of 0.01 with financial performance. -HR technology only has a positive $\mathrm{R}^{2}$ of 0.12 with relative ranking of the HRM manager and no significant $\mathrm{R}^{2}$ with financial performance.

This leads us to the following propositions for the European dataset:

Proposition 1: all five domains of HRM competencies - strategic contribution, personal credibility, HR delivery, business knowledge, and HR technology - have a positive effect on performance.

Brockbanck et al. (2002) suggest that strategic contribution is the most important HRM domain of all five domains mentioned before, represented by the highest score of 0.05 on the $\mathrm{R}^{2}$ between a competency domain and the financial performance of an organization. Other domains such as personal credibility, HR delivery, business knowledge, and HR technology are supportive to the strategic contribution of the HR function and its professionals. This leads to the second proposition in this analysis:

Proposition 2: strategic contribution is the most important domain for the HR function 
and its HRM professionals. The effect of strategic contribution on financial performance is bigger than the effect of other domains.

\section{Methodology}

In this paper we concentrate on Europe. We will focus on the identification of core competencies for the HRM function and its HRM professionals in combination with the added value of these competencies in Europe, as perceived by relevant (internal) stakeholders of an organization. This results in the following key questions:

(1) What are the core competencies for the HRM function (and its HRM professionals) perceived by relevant clients in an organization (HR staff and management) in Europe?

(2) What is the perceived added value of these HRM competencies to the performance of an organization in Europe?

We will focus our research on the five domain factors presented in the previous section: strategic contribution, personal credibility, HR delivery, business knowledge, and HR technology.

As mentioned above, two separate items measure performance in this paper:

1. Overall, compared with the other HR professionals whom you have known, how do you compare? (relative ranking of the perceived HR-function performance)

2. Compared to the major competitor in "your business" in the last three years, how has "your business" performed financially? (financial competitiveness)

The Human Resource Competency Study examined the competencies of human resource professionals and their contribution to business results and was processed online (web-based). In order to give the reader an impression of the type of questions used in the survey, we will give some examples of the items used in this European study: -For each of the HR practices listed below (staffing, development, performance appraisal, rewards, communication, organizational design, HR and technology, measurement of HR, and workplace policies), please indicate the extent to which you [the HRM manager, eds.] are capable of using 
the practice to build success in "your business"? (5-point scale; $1=$ to very little extent and $5=$ to very large extent.)

- $\quad$ Please indicate the extent to which you [the HRM manager, eds.] agree with the following statements about your role in managing change: e.g. encourage others to be creative, clarify business goals, are visionary, facilitate change processes (5point scale; $1=$ to very little extent and $5=$ to very large extent).

- $\quad$ To what extent do you agree with the following statements about your personal work style [the work style of the HRM manager, eds.]? e.g. Meet commitments, have a track record of results, demonstrate high integrity, and live the values of the firm (5-point scale; $1=$ to very little extent and $5=$ to very large extent).

The respondents of the European HRCS were HRM professionals and line managers of multinational companies located in Europe. The Michigan University's Business School closely cooperated in this study with the Rotterdam School of Management, in particular with respect to the preparation of mailing lists of senior HR managers in Europe. The mailing list of one specific MBA program at the Rotterdam School of Management called the HR Leadership Class, a MBA program aimed at HR managers with five to ten years of work experience in HRM and with capacities to become HR directors in the near future, was used to contact senior HR directors in large firms operating in Europe (e.g. Shell, Unilever). These senior HR directors are the contact persons (or participant raters) in this study. These participant raters were invited to participate in our research and asked to select related HR managers and non-HR managers or specialists (e.g. account manager, controller, marketing manager) in their own organization to participate as well. The application of multiple respondents in this so-called 360-degree approach enables unique research control on the (inter) reliability of the respondents' answers (e.g. Gerhart, Wright and McMahan, 2000). For the effectiveness of HR departments Biemans (1999) found significant differences between three groups of stakeholders in an organization: employees, managers, and personnel managers. The perception of the three groups of the performance of the HR department varied significantly. Overall, personnel managers were found to be more 
positive about the performance of the HR department than employees and managers. The results emphasize the importance of using multiple respondent groups in contrast to the dominating single respondent approaches, often focused on HR managers, of the majority of prior empirical research on HR effectiveness. In this study we will focus on two different groups: HRM managers versus non-HRM managers. A distinction between those working in the HR department (HRM raters) and those working in other areas on the organization (non-HRM raters) will be used in the further analyses in this paper: -HRM managers or HR related specialists $(n=255)$; Non-HRM managers and specialists $(n=428)$.

The empirical survey data $(\mathrm{N}=683)$ were collected in 2001 and stem from organizations operating in different branches of industry located in European countries: -UK $(n=279)$, the Netherlands $(n=123)$, Switzerland $(n=89)$, Belgium $(n=38)$ and Germany $(n=30)$; - Scotland, Cyprus, Finland, France, Spain, Sweden and Macedonia (each country had less than 30 observations). Above, ' $n$ ' represents the number of respondents.

The organizations in the European HRCS belong to the following industries: chemicals \& pharmaceuticals $(n=112)$, agriculture $(n=104)$, financial services $(n=104)$, communications and high technology $(n=85)$, general manufacturing $(n=85)$, services $(n=81)$, automotive $(n=$ 51), utilities ( $n=32$ ), petroleum \& mining $(n=20)$, and retail $\&$ wholesales $(n=3)$. Again, ' $n$ ' represents the number of individual respondents.

Unfortunately, we were not able to include the employees' perspective. Guest (1999) argues that the employees' perception of human resource management practices is crucial for the impact of HRM on performance. This study relies heavily on subjective data from HRM managers and non-HRM managers - staff and line managers representing the employer's interests - and might therefore just reveal one side of the coin. It is possible that there are systematic errors in the data, for example, caused by a social desirability bias. The latter issue reflects the respondent's tendency to be too positive about the results because of his or her own interests within the organization. We assume that this type of error in this study is systematic in 
a way that all respondents have a tendency to present 'excellent' results that are slightly overestimated. Some people argue that objective data (e.g. productivity, product/service quality, sales, profits) overcome this reliability issue, in particular with respect to whether the data presented are 'rhetoric' versus 'reality'. A problem with most accounting-based (e.g. GRATE or gross rate of return on capital) and market-based performance measurements (e.g. Tobin's $q$ ) is mentioned by Kanfer (1994) and Guest (1997) and relates to proximal-distal notions. They argue that linking HRM and financial performance directly, both accounting-based and marketbased indicators, does not provide reliable results in terms of the casual link between HRM and performance. Significant relationships between HR practices and firm performance, for example presented in Huselid's (1995) study, are more likely to represent a case of reversed causality (e.g. Boselie, Paauwe and Jansen, 2001). Therefore, both Kanfer (1994) and Guest (1997) suggest focusing on outcome indicators that are more closely located - proximal - to HRM interventions: HRM outcomes (e.g. employee commitment, satisfaction, motivation, perceived performance).

\section{Results}

The independent variables in this analysis were constructed from the global HRCS dataset. Data reduction analysis in the form of factor analysis with a Correlation Matrix method and Varimax Rotation was used with the statistical program SPSS on the global HRCS set (1780 observations of global Associate raters in the functions of general management, finance \& accounting, manufacturing, marketing \& sales, and planning). 111 competency variables were factored and sorted by factor loadings ( $>0.3$ ). The outcome was five distinct domains. From the five distinct domain factors all variables with factor loadings greater than 0.5 were selected and included in further analyses. Variables with factor loading scores below 0.5 dropped out $(n=6)$. The domain scores were computed for each case where more than $75 \%$ of the variables had answers. This is a common statistical technique that is used to prevent bias scores (Brockbanck and Ulrich, 2002). Factor scores were also computed in this manner. See Table 1 for overview. 
Table 1

Data Reduction

\begin{tabular}{|l|c|c|c|}
\hline & $\begin{array}{c}\text { Variables with } \\
\text { loadings }>0.5\end{array}$ & $\begin{array}{c}\text { Minimum number of } \\
\text { variables answered } \\
(\sim 75 \%)\end{array}$ & $\begin{array}{c}\text { Number of Factors } \\
\text { within each Domain }\end{array}$ \\
\hline $\begin{array}{l}\text { Domain I } \\
\text { 'strategic contribution' }\end{array}$ & 39 items & 29 items & 4 \\
\hline $\begin{array}{l}\text { Domain II } \\
\text { 'personal credibility' }\end{array}$ & 20 items & 15 items & 3 \\
\hline $\begin{array}{l}\text { Domain III } \\
\text { 'HR delivery' }\end{array}$ & 23 items & 17 items & 3 \\
\hline $\begin{array}{l}\text { Domain IV } \\
\text { 'business knowledge' }\end{array}$ & 19 items & 14 items & 1 \\
\hline $\begin{array}{l}\text { Domain V } \\
\text { 'HR technology' }\end{array}$ & 4 items & 3 items & $\mathbf{1 5}$ factors \\
\hline TOTAL: & $\mathbf{1 0 5}$ items & $\mathbf{7 8}$ items & \\
\hline
\end{tabular}

\subsection{Descriptives}

The domain and factor scores of the European survey are presented in Table 2. It is obvious that the respondents rank personal credibility highest, followed by HR delivery and strategic contribution. Business knowledge and HR technology reveal lower scores on average. We have to be very careful with the interpretation of these findings. A high score on personal credibility does not automatically mean that this specific domain factor is more important than for example the domain factor strategic contribution. We interpret the findings in terms of 'general satisfaction' of the respondents with respect to the specific construct. Further analyses on the added value of the factors can provide us insights with respect to their perceived contribution to performance.

HR respondents reveal higher significant scores on three out of five domains if we look at a simple t-test in Table 2. The three domains are strategic contribution, personal credibility and HR technology. These higher scores might be a case of social desirability bias as mentioned earlier and similar to the findings in the research of Biemans (1999). In particular, HR respondents score higher than the non-HR respondents on culture management, strategic decision-making, fast change, gets results, personal communication, development and HR technology. 
Table 2

Descriptives: Domain and Factor Scores European HRCS

\begin{tabular}{|c|c|c|c|c|}
\hline & Mean Total & Non-HRM & $H R M$ & $t$ \\
\hline Strategic contribution: & $3.69(0.65)$ & $3.63(0.62)$ & $3.81(0.70)$ & ++ \\
\hline 1. culture management & $3.72(0.74)$ & $3.64(0.70)$ & $3.86(0.77)$ & ++ \\
\hline 2. strategic decision making & $3.78(0.67)$ & $3.71(0.64)$ & $3.89(0.70)$ & ++ \\
\hline 3. fast change & $3.71(0.72)$ & $3.65(0.71)$ & $3.81(0.73)$ & ++ \\
\hline 4. market driven connectivity & $3.35(0.78)$ & $3.28(0.76)$ & $3.45(0.81)$ & + \\
\hline Personal credibility: & $4.11(0.57)$ & $4.05(0.56)$ & $4.21(0.58)$ & ++ \\
\hline 1. effective relationships & $4.14(0.65)$ & $4.10(0.64)$ & $4.20(0.67)$ & no \\
\hline 2. gets results & $4.10(0.57)$ & $4.03(0.56)$ & $4.23(0.58)$ & ++ \\
\hline 3. personal communication & $4.05(0.73)$ & $3.95(0.75)$ & $4.20(0.69)$ & ++ \\
\hline HR delivery: & $3.70(0.64)$ & $3.67(0.60)$ & $3.75(0.69)$ & no \\
\hline 1. development & $3.75(0.72)$ & $3.69(0.68)$ & $3.87(0.76)$ & ++ \\
\hline 2. HR structure \& measurement & $3.50(0.74)$ & $3.46(0.71)$ & $3.58(0.78)$ & + \\
\hline 3. Staffing & $4.05(0.67)$ & $4.06(0.64)$ & $4.03(0.73)$ & no \\
\hline 4. performance management & $3.47(0.92)$ & $3.43(0.87)$ & $3.54(0.99)$ & no \\
\hline Business knowledge: & $3.36(0.67)$ & $3.34(0.61)$ & $3.40(0.77)$ & no \\
\hline 1. value chain & $3.15(0.73)$ & $3.11(0.69)$ & $3.22(0.80)$ & no \\
\hline 2. value proposition & $3.48(0.73)$ & $3.43(0.67)$ & $3.56(0.81)$ & + \\
\hline 3. labour & $3.65(1.01)$ & $3.72(0.93)$ & $3.52(1.12)$ & - \\
\hline HR technology: & $3.04(0.96)$ & $2.90(0.94)$ & $3.27(0.94)$ & ++ \\
\hline $\begin{array}{l}\text { Scores: } 1=\text { low } 5=\text { high } \\
\text { Standard Deviation between brackets } \\
t \text {-test for testing significant differences bet } \\
+=H R \text { respondent higher than non-HR re } \\
==H R \text { respondent lower than non-HR res } \\
N=683\end{array}$ & $\begin{array}{ll}\text { lent; } & ++p \\
\text { nt; } & --p\end{array}$ & $\begin{aligned} \text { pondents: } & \\
+ & p<0 \\
-p & <0\end{aligned}$ & & \\
\hline
\end{tabular}

If we look more closely at the descriptive factor scores of the European HRCS in Table 2 we can conclude that effective relationships, gets results, personal communication, and staffing demonstrate relatively high scores. The lowest scores on factors in this study are HR technology, value chain, and market driven connectivity. Overall, the scores are relatively high if we take into account the large number of observations $(N=683)$ and the nature of the scale being used (5-points scale).

Table 3 represents the frequencies of the type of respondents (HRM raters versus nonHRM raters) and the descriptive statistics of the two performance measurements used in this study. The respondents tend to be quite optimistic about these indicators. On average, the 
relative ranking of the perceived HRM-function performance is considered to be at the top- $25 \%$ of all the HRM professionals known to the respondent. This could be an indication of an overestimation of the respondents, a form of systematic error, or a problem with respect to the representativeness of the organizations involved. It might be possible that only successful organizations participated in this study. The latter issue appears to be supported by the relatively high scores on the financial competitiveness. There are no significant differences between HR and non-HR respondent groups.

Table 3

Frequencies and Descriptives

Frequency Percent

Type of respondent:

-HRM raters 255

$37 \%$

-non-HRM raters

428

$63 \%$

(Dummy: non-HRM $=1$ \& $H R M=0$ )

Performance (1): relative ranking of the perceived HR-function performance

Overall competencies of HR professional: overall, compared with the other HR professionals whom you have known, how do you compare?

(20-points scale; $1=$ bottom $5 \%$ and $20=$ top $5 \%$ )

Mean Total $=16.17($ std, dev $=3.07)$

Mean non-HR respondent $=16.01$ (std. dev. $=3.12$ )

Mean HR respondent $=16.45$ (std. dev. $=2.96$ )

No significant difference between Non-HR and HR respondents

\section{Performance (2): financial competitiveness}

Compared to the major competitor in "your business" in the last three years, how has "your business" performed financially?

(5-points scale; $1=$ much worse and $5=$ much better).

Mean Total $=3.55$ (std. dev. $=0.83$ )

Mean non-HR respondent $=3.51$ (std. dev. $=0.72)$

Mean HR respondent $=3.61$ (std. dev. $=0.99$ )

No significant difference between Non-HR and HR respondents

Unfortunately we were not able to include control variables like geographical location (country in which the company is located), size of the firm, and branch of industry, as a result of lack of reliable data in case of firm size and as a result of lack of data points per entity in case of country and branch of industry. 


\subsection{Correlations}

The correlations between type of respondent, performance indicators, and HRM domains are presented in Table 4 . We set out to focus on the most notable significant relations in this Table. First, we find strong correlations between the performance indicator relative ranking of the perceived HR-function performance and all the five domains. Second, we find a positive relationship between relative ranking of the HR-function (performance 1) and financial competitiveness (performance 2). Third, the domain of strategic contribution is positively correlated with financial competitiveness, while the domain of HR technology is negatively correlated with this performance outcome. Fourth, all domains reveal relatively high correlations with each other. Finally, the average scores on strategic contribution, personal credibility, and HR technology are lower for non-HRM raters than their colleagues from the HR department.

Table 4

Correlations

\begin{tabular}{|c|c|c|c|c|c|c|c|c|c|}
\hline & & 1. & 2. & 3. & 4. & 5. & 6. & 7. & 8. \\
\hline 1. & Non-HRM rater & 1.00 & & & & & & & \\
\hline 2. & Performance (1) & -0.07 & 1.00 & & & & & & \\
\hline 3. & Performance (2) & -0.06 & $0.13^{* *}$ & 1.00 & & & & & \\
\hline 4. & Domain (I) & $-0.14^{\star \star}$ & $0.54^{\star \star}$ & $0.10^{\star}$ & 1.00 & & & & \\
\hline 5. & Domain (II) & $-0.14^{\star \star}$ & $0.62^{\star \star}$ & 0.05 & $0.78^{\star \star}$ & 1.00 & & & \\
\hline 6. & Domain (III) & -0.07 & $0.50^{\star \star}$ & 0.04 & $0.76^{\star \star}$ & $0.65^{\star \star}$ & 1.00 & & \\
\hline 7. & Domain (IV) & -0.05 & $0.39^{\star \star}$ & 0.07 & $0.60^{\star \star}$ & $0.50^{\star \star}$ & $0.66^{\star \star}$ & 1.00 & \\
\hline 8. & Domain $(V)$ & $-0.19^{\star \star}$ & $0.25^{\star \star}$ & $-0.10^{\star}$ & $0.42^{\star \star}$ & $0.33^{\star \star}$ & $0.50^{\star \star}$ & $0.48^{\star \star}$ & 1.00 \\
\hline
\end{tabular}




\subsection{Regression analyses}

We are particularly interested in the main effects of the five domains on performance when all domains are included in the analysis. The correlation matrix reveals relatively high correlations - varying between 0.33 and 0.78 - between the five domains. This means that there is significant overlap of the domains. For example, strategic contribution overlaps with personnel credibility (correlation of 0.78 ) and HR delivery (correlation of 0.76 ). We want to know which domain is contributing most to performance taking into account the other domains. In practice presumably elements of all five domains are applied and it is also therefore we want to know which domains are most crucial taking into account their interdependency. Regression analysis at least partly copes with the relatively high correlations amongst the independent variables (domains).

What are the effects of the five domains on performance? The results of multiple regression analysis are shown in Table 5 and 6 . We used linear regression in SPSS to study the overall effects on performance. The independent variables (domains) are all standardized. If we look more closely at Table 5 we find a positive relation between the HR domains personal credibility $\left(\beta=0.51^{\star \star *}\right)$ and $\mathrm{HR}$ delivery $\left(\beta=0.17^{\star \star}\right)$ and the 'relative ranking of the perceived HR-function performance'. These effects are more or less consistent for the regression analysis on non-HRM rater data in comparison to the regression analysis on HRM rater data. The difference between non-HRM raters (e.g. finance \& accounting, general management, manufacturing \& production, marketing \& sales, planning, research \& development) and HRM raters with respect to the relative ranking of the HR function is manifested in the effect of business knowledge. Respondents who are related to HRM consider the domain business knowledge to be essential for the relative ranking of the HR function $(0.12 \mathrm{U})$, while Non-HRM raters don't. This is a first, although statistically weak, indication for differences between those who are related to the HR function and those who're not, and an indication for some problems related to interreliability in empirical HR research (e.g. Biemans, 1999; Gerhart et al., 2000). 
Overall, we conclude that personal credibility and HR delivery are crucial for the qualification and added value of the HR function in an organization.

Table 5

Domain Effects on Relative Ranking HR Function

\begin{tabular}{|c|c|c|c|}
\hline & $\begin{array}{l}\text { Full Model (1) } \\
(\beta)\end{array}$ & $\begin{array}{c}\text { Non-HRM (2) } \\
(\beta)\end{array}$ & $\begin{array}{c}\text { HRM (3) } \\
(\beta)\end{array}$ \\
\hline Non-HRM rater & 0.17 & - & - \\
\hline \multicolumn{4}{|l|}{ Domain (I) } \\
\hline $\begin{array}{l}\text { Strategic } \\
\text { Contribution }\end{array}$ & 0.02 & 0.07 & -0.03 \\
\hline \multicolumn{4}{|l|}{ Domain (II) } \\
\hline Personal Credibility & $0.51^{* \pi *}$ & $0.54^{\star * *}$ & $0.42^{\star \star \star}$ \\
\hline \multicolumn{4}{|l|}{ Domain (III) } \\
\hline HR Delivery & $0.17^{* *}$ & $0.17^{*}$ & $0.16 \dagger$ \\
\hline \multicolumn{4}{|l|}{ Domain (IV) } \\
\hline $\begin{array}{l}\text { Business } \\
\text { Knowledge }\end{array}$ & 0.02 & -0.04 & $0.12 \dagger$ \\
\hline \multicolumn{4}{|l|}{ Domain $(V)$} \\
\hline HR technology & -0.02 & -0.06 & 0.08 \\
\hline$F$ & $77.88^{* * *}$ & $65.18^{* * *}$ & $31.43^{* * *}$ \\
\hline Adj. $R^{2}$ & 0.42 & 0.45 & 0.39 \\
\hline $\mathrm{N}$ & 635 & 393 & 241 \\
\hline
\end{tabular}

$\dagger p<0.10^{*} p<0.05^{* *} p<0.01^{* * *} p<0.001$

Linear Regression in SPSS

Domain factors in the analyses are all standardized.

$\beta=$ standardized coefficients or Beta's

The full model in Table 6 suggests a positive relationship between the HR domain strategic contribution $\left(\beta=0.22^{\star *}\right)$ and financial competitiveness of an organization. HR technology is negatively related to financial competitiveness $\left(\beta=-0.20^{\star \star \star}\right)$. This might be an indication for the high costs involved with the implementation of new HR technology (e.g. eHRM, web-based organization). HR technology such as e-HRM is still relatively young and therefore this technology might not contribute to firm performance yet. Within the next couple of years this might change. The regression analyses in Table 6 reveal significant differences between HRM and non-HRM raters. In model 2, which is focused on non-HRM respondents, 'strategic contribution' is considered to be positively related to financial performance. In contrast, 
HRM respondents consider 'business knowledge' to be crucial for financial competitiveness, while HR technology is negatively related to this performance outcome (see model 3 in Table 6). Comparing the two groups of raters in this study we can conclude that there is a difference in perceived HR competencies driving financial performance.

Table 6

Domain Effects on Financial Competitiveness

\begin{tabular}{|c|c|c|c|}
\hline Full Model & $\begin{array}{c}\text { (1) Non-HRM } \\
(\beta)\end{array}$ & $\begin{array}{c}\text { (2) HRM } \\
(\beta)\end{array}$ & $\begin{array}{c}\text { (3) HRM } \\
(\beta)\end{array}$ \\
\hline Non-HRM rater & -0.01 & - & - \\
\hline $\begin{array}{l}\text { Domain (I) } \\
\text { Strategic } \\
\text { Contribution }\end{array}$ & $0.22^{\star *}$ & $0.39^{* * *}$ & 0.05 \\
\hline $\begin{array}{l}\text { Domain (II) } \\
\text { Personal } \\
\text { Credibility }\end{array}$ & -0.08 & -0.10 & -0.06 \\
\hline $\begin{array}{l}\text { Domain (III) } \\
\text { HR Delivery }\end{array}$ & -0.01 & -0.06 & 0.03 \\
\hline $\begin{array}{l}\text { Domain (IV) } \\
\text { Business } \\
\text { Knowledge }\end{array}$ & 0.08 & -0.08 & $0.22^{*}$ \\
\hline $\begin{array}{l}\text { Domain (V) } \\
\text { HR technology }\end{array}$ & $-0.20^{\star * \star *}$ & -0.09 & $-0.29^{\star \star \star \star}$ \\
\hline$F$ & 5.01 & $4.74^{\star \star}$ & $4.00^{\star \star}$ \\
\hline Adj. $R^{2}$ & 0.04 & 0.05 & 0.06 \\
\hline $\mathrm{N}$ & 614 & 383 & 230 \\
\hline
\end{tabular}

Proposition 1 on the positive impact of all domains of HRM competencies on

performance is partly accepted. Personal credibility and HR delivery appear to increase the HR function's evaluation. These two HRM competencies are crucial for the positioning of the HR department in an organization. High scores on credibility and delivery create a seat at the table instead of HRM being on the table (Brockbank et al., 2002). 'Strategic contribution' is the HR competency that leads to an increased financial competitive position according to non-HRM respondents, while HRM raters think it's the HR competency 'business knowledge' that is necessary for increased competitiveness of the firm. 
Proposition 2, claiming strategic contribution to be the most important domain, appears to be true when looked at the 'customers' of the HR function (the non-HRM raters or those working in finance \& accounting, general management, marketing, production and manufacturing etc.). These findings support proposition 2. Unfortunately, HRM raters have a different opinion. They are convinced that business knowledge leads to financial performance and knowledge of HR technology affects the organization's position negatively.

As mentioned earlier on in this paper we were not able to control for country and firm size effects as a result of lack of data on firm size and limited number of data per country. We were able to test for company effects through aggregation of the individual level data to firm level. The 683 individual responses stem from 40 multinational companies operating in different European countries. The aggregated data to firm level $(N=40)$ reveal similar effects as the analyses on individual respondent level. Again personal credibility is significantly and positively related to the ranking of the HR function $(p<0.01)$. HR delivery is also positively related to this ranking, but unfortunately it's not significant $(p=0.12)$. The full model for firms on financial competitiveness reveals a negative relationship between HR technology and the financial position of the firm $(p<0.05)$. Neither strategic contribution nor business knowledge were significantly related to financial competitiveness. This might be caused by the limited number of data $(\mathrm{N}=40)$ in these analyses on firm level.

There are at least three significant limitations in this study. First, the data are crosssectional and we should therefore be very careful with assuming certain causal relationships between domains and performance. Second, the analyses are built on perception data. In particular the performance indicators might not be reliable. How do we know for sure that the respondents were completely honest and well informed about their organization's performance? This is an issue in most of our survey research. Finally, we were limited with respect to the inclusion of more control variable like 'size of the organization' as a result of 
missing data. We expect significant differences in the outcomes if we explicitly take the variable size (number of employees) into account.

\section{Summary and Discussion}

Overall we conclude that the empirical results presented in this paper suggest positive impact of personal credibility and HR delivery on the ranking of the HR function. These findings correspond with prior research of Kelly and Gennard (1996), who argue that personnel directors require professional competence in HR proactively contributing to solving business problems (a form of HR delivery) and social skills in developing effective interpersonal relations with other board directors (being part of the personal credibility notion in this paper). For non-HRM raters strategic contribution is the HRM competency necessary for improving (or maintaining) the financial competitiveness of an organization. The HRM raters in this study or those who work directly for or within the HR department consider business knowledge to be crucial for the financial position of an organization. The latter group sees knowledge of HR technology such as e-HRM negatively related to financial competitiveness, presumably because of the relatively high start-up costs.

Schuler and Jackson (2001) argue that the roles of the HR department and its professionals are changing substantially and that the competencies required of these professionals to play these new roles are also changing rapidly. The knowledge, skills, and abilities of the people in the human resource department play an important role in building effective HRM (Schuler et al., 2003). Just like Schuler and Jackson a whole range of authors in this area is increasingly emphasizing the more strategic and change oriented competencies and roles of the HR-function (e.g. Skinner and Mabey, 1997). However, based on our findings we argue that the trustworthiness of HR-managers and his/her skills in delivering the basics in the area of staffing, development and administration are still indispensable and essential for being perceived as effective. This is reflected by the high frequency of the domains of Personal Credibility and HR Delivery. Tyson's (1987) clerk of work and Ulrich's (1997) administrative 
expert and employee champion role function as important 'hygiene' factors for HR departments. In a range of case-studies, carried out among Dutch based multinational companies (Paauwe, 1996) we established that HR-managers and their departments are allowed to fulfill more strategic and change oriented roles. However, they only got the credits to do so, provided that the basic HRM processes (e.g. staffing, rewarding, appraisal) were taken care of in a costeffective way and carried out at a high quality level. These basic activities were highly appreciated by regular line management and generated credits for being 'at the table' and being allowed to interfere on more strategic and organizational change issues. More recent survey based research by Biemans (1999) for the Netherlands and Caldwell (2003) for the UK confirms these findings and reaffirms the still important role of 'service provider'. Nowadays many European countries face an economic decline implying that companies have to reorganize, downsize and experience continuous change in order to stay in business. So, when times get rough, the strategic contribution, inclusive the focus on implementing 'fast change', will gain importance. The main challenge facing the HR manager will be to take care -at the same timeof continuing HR delivery and maintaining credibility, while at the same time being involved in implementing and facilitating all kinds of changes in order to enable downsizing and/or corporate restructuring. This implies a lot of emphasis upon keeping moral standards in terms of fairness and legitimacy (see also Winstanley and Woodall, 2000), otherwise the credibility will diminish and so the credits for implementing strategic change will increasingly be lost.

For the near future we expect the HRM manager to be an entrepreneur, who is willing to take risks, is customer oriented, has business knowledge and specific HR knowledge, is responsible and accountable for HR results, is open minded, and knows how to motivate and persuade people and implement and facilitate change. In combination with web enabled HR service delivery, often in combination with centralized shared services, we foresee a development by which the time spent on the traditional transactional HR activities will decrease, while at the same time the HR professional is required to spend more time as a change 
facilitator. Several big internationally operating companies (e.g. Unilever, Proctor \& Gamble) have already begun to change the profile of their HR professionals working in the different subsidiaries. This is in line with the claim put forward by a range of authors like Dyer and Shafer (1999), Boxall and Purcell (2003), and Paauwe and Boselie (2003). They all argue that human resource management is not primarily about performance, but about issues like willingness to change and improving flexibility and adaptability of the organization as well. This ability to change is also referred to as HRM agility (Dyer and Shafer, 1999), HRM flexibility (Boxall and Purcell, 2003) and long-term viability (Paauwe, 2004).

Looking back on the last two decades of empirical research in the HRM area, the dominant theme was the relationship between HRM and Performance. But from now on we expect more focus on the whole issue of how HR competencies can contribute to agility and long term viability. After all the linkage between HRM and performance is difficult to establish and fraught with measurement errors. The relationship between HRM interventions and for example willingness to change, commitment, and levels of trust is a less distal relationship, a bit easier to establish and probably a lot more relevant for both academics and practitioners. 


\section{References}

Biemans, P.J. (1999) Professionalisering van de personeelsfunctie: een empirisch onderzoek bij twintig organisaties, Eburon, Delft.

Boselie, P., Paauwe, J. and Jansen, P.G.W. (2001) "Human resource management and performance: lessons from the Netherlands," The International Journal of Human Resource Management, Vol.12, No.7, pp.1107-1125.

Boxall, P. and Purcell, J. (2003) Strategy and human resource management, Palgrave Macmillan, New York.

Brewster, C. and Larsen, H.H. (2000) Human resource management in northern Europe: Trends, dilemmas and strategy, Blackwell Publishers, Oxford.

Brockbank, W. and Ulrich, D. (2002) The new HR agenda: 2002 HRCS executive summary, University of Michigan Business School.

Brockbank, W., Sioli, A. and Ulrich, D. (2002) So we are at the table! Now what, working paper, University of Michigan, (http://webuser.bus.umich.edu/Programs/hrcs/res NowWhat.htm)

Caldwell, R (2003). "The changing roles of personnel managers: Old ambiguities, new uncertainties", Journal of Management Studies Vol.40, No.4, June, pp. 983-1004.

Caroll, S.J. (1991) The new HRM roles, responsibilities, and structures, in: Schuler,

R.S. (ed.) Managing human resources in the information age, Washington, D.C.: Bureau of National Affairs, pp.204-226.

Dyer, L. and Shafer, R. (1999) Creating organizational agility: implications for strategic human resource management. In: Wright, P., Dyer, L., Boudreau, J. and Milkovich, G. (eds) Research in Personnel and Human Resource Management (Supplement 4: Strategic Human Resource Management in the Twenty First Century), JAI Press, Stamford, CT and London.

Gerhart, B., Wright, P.M. and McMahan, G. (2000) "Measurement error in research on the human resource and firm performance relationship: further evidence and analysis", Personnel Psychology, Vol.53, No.4, pp. 855-872.

Guest, D.E. (1997). "Human resource management and performance: a review and research agenda", The International Journal of Human Resource Management, Vol.8, No.3, pp. 263276.

Guest, D.E. (1999). "Human resource management: the workers' verdict". Human

Resource Management Journal, 9, pp. 5-25.

Huselid, M.A. (1995) "The impact of human resource management practices on turnover, productivity, and corporate financial performance", Academy of Management Journal, Vol.38, No.3, pp.635-672.

Huselid, M.A., Jackson, S.E. and Schuler, R.S. (1997) "Technical and strategic human resource management effectiveness as determinants of firm performance", Academy of Management Journal, Vol. 40, No.1, pp.171-188.

Kanfer, R. (1994). Work motivation: new directions in theory and research, pp.158-188, in: C.L. Cooper and I.T. Robertson (eds.) (1994) Key reviews in managerial psychology. New York: Wiley.

Kelly, J. and Gennard, J. (1996) "The role of personnel directors on the board of directors", Personnel Review, Vol. 25, No. 1, pp. 7-24.

Paauwe, J. (1996) "Key issues in strategic human resource management: lessons from The Netherlands", Human Resource Management Journal, Vol. 6, No. 3, pp. 76-93.

Paauwe, J. and Boselie, P. (2003) 'Challenging 'strategic' human resource management and the relevance of the institutional setting", Human Resource Management Journal, Vol.13, No.3, pp. 56-70.

Paauwe, J. (2004, forthcoming) Human resource management and performance: Unique approaches for achieving long term viability, Oxford University Press, Oxford. 
Schuler, R.S. (1990) "Repositioning the human resource function: transformation or demise?" Academy of Management Executive, Vol. 4, No.3, pp. 49-59.

Schuler, R.S. and Jackson, S.E. (2001) HR roles, competencies, partnerships and structure, in: $M$. Warner and M. Poole (eds.) International encyclopaedia of business and management, 2 edition, ITP, London.

Schuler, R.S., Jackson, S.E. and Fendt, J. (2003) HR leader, staff and department, in:

R. Berndt (ed) (2003) Leadership in difficult times, Springer Press, Berlin.

Skinner, D. and Mabey, C. (1997) "Managers' perceptions of strategic HR change", Personnel Review, Vol. 26, No. 6, pp. 467-484.

Storey, J. (1992) Developments in the management of human resources, Blackwell Publishers, Oxford.

Teo, S.T.T. (2002) "Effectiveness of a corporate HR department in an Australian public sector entity during commercialisation and corporatization", The International Journal of Human Resource Management, Vol.13, No.1, pp. 89-105.

Tyson, S. and Fell, A. (1986) Evaluating the personnel function, Hutchinson, London.

Tyson, S. (1987) "The management of the personnel function", Journal of Management Studies, Vol.24, No.5, pp. 523-532.

Ulrich, D. (1997) Human resource champions, Harvard Business School Press, Boston, MA.

Winstanley, D. and Woodall, J. (2000) "The ethical dimension of human resource management", Human Resource Management Journal, Vol.10, No.2, pp.5-20. 